\section{A comparison of pro- pranolol and diazepam for preoperative anxiolysis}

J.B. Dyck FRCPC, F. Chung, FRCPC
The effectiveness of propranolol, a nonsedating anxiolytic premedication, was studied by monitoring preoperative anxiety and postoperative recovery of cognitive function in 92 healthy ASA physical status I females aged 15-42 yr undergoing outpatient dilatation and curretage $(D \& C)$ for therapeutic abortion. In a randomized double-blind design. patients received one of the following oral medications $1-1.5 \mathrm{hr}$ preoperatively: (1) diazepam $10 \mathrm{mg}(n=31)$; (2) propranolol $80 \mathrm{mg}(n=$ 31); (3) placebo $(n=30)$. Anxiety throughout the hospital stay was monitored using the State-Trait Anxiety Inventory (STAI). Postoperative cognitive recovery was assessed using the digit span and Trieger tests. STAI anxiery levels were recorded on admission to hospital, immediately before entering the operating room, and two hours postoperatively. There was no difference among the anxiolytic properties of the three medications and all three patient groups showed a significant decrease in anxiery levels after administration of the medication. Tests of cognitive function after anaesthesia showed the fastest return to baseline status in patients receiving propranolol, possibly because beta adrenergic blockade blunted the autonomic signs of light anaesthesia and less anaesthetic was administered. None of the study premedications was demonstrated to have an anxiolytic advantage, but propranolol did offer a faster return of cognitive function in the postoperative period.

Nous avons voulu évaluer l'efficacité du propranolol à titre de prémédication anxiolyrique non-sédative en mesurant le degré d'anxiété préopératoire et la rapidité de la récupération

\section{Key words}

PREMEDICATION: diazepam, propranolol; SURGERY: ambulatory.

From the Department of Anaesthesia, Toronto Western Division, Toronto Hospital, University of Toronto, Toronto, Ontario, Canada.

Address correspondence to: Dr. F. Chung, Department of Anaesthesia, Toronto Western Division, The Toronto Hospital, Toronto, Ontario, Canada M5T 2S8.

Accepted for publication 12th April, 1991. postopératoire des fonctions cognitives. Quatre-vingt douze femmes de 15 à 42 ans de classe ASA I, candidates d une dilatation cervicale el curetage pour avortement en externe, se sont prêtées à notre étude. Après randomisation à double-insu, elles prenaient par la bouche soit $10 \mathrm{mg}$ de diazépam $(n=31)$, soit $80 \mathrm{mg}$ de propranolol $(n=31)$, soit un placebo $(n=30)$ et ce, de 60 a 90 minutes avant l'intervention. Nous mesurions le niveau d'anxiéré a l'admission, juste avant d'entrer en salle d'opération et deux heures après l'intervention en utilisant le "State-Trait Anxiety Inventory (STAI)". Le "digit span ", test mnémonique numérique et le test de Trieger nous servaient d mesurer les fonctions cognitives avant et après l'opération. Les trois médications utilisés n'ont pas démontré de propriétés anxiolytiques différentes, les niveaux d'anxiété allant décroissant dans les trois groupes à partir de l'admission à l'hôpital. Par contre, après l'opération, les fonctions cognitives retournaient plus vite a la normale chez les patientes du groupe propranolol, peut-être parce que le blocage $\beta$-adrénergique avaif permis de surestimer la profondeur de l'anesthésie pendant l'intervention entraînant l'utilisation de moindres doses d'anesthésique.

Outpatients often do not have the benefit of a reassuring visit by the anaesthetist the night prior to surgery, or the pharmacologic support of any anxiolytic premedication. Normal preoperative anxiety in a healthy outpatient is not life-threatening but does add an unnecessary stress to the hospital stay. The sedative properties of anxiolytic premedications may extend into the postoperative period and delay discharge from hospital. A premedication which has anxiolytic properties and does not cause sedation would be a useful addition to the anaesthetic armamentarium.

The anxiolytic properties of propranolol are not as widely recognized as its cardiovascular effects. Beta adrenergic blockers have been shown to be effective in the prevention of stage fright, ${ }^{\prime}$ and in the treatment of pathological anxiety neuroses. ${ }^{2}$ Sedation and impairment of psychomotor skills are minimal after administration of propranolol. ${ }^{3}$ Conversely, stimulation of the beta receptors with terbutaline has been shown to increase anxiety. ${ }^{4}$ 
This study was designed to examine the effectiveness of propranolol as an anxiolytic agent in the preoperative period relative to diazepam and placebo. We also compared the duration of cognitive impairment and haemodynamic changes that resulted from the different premedications.

\section{Methods}

After approval by the institutional ethics committee informed consent was obtained from 92 ASA physical status I females undergoing therapeutic suction dilatation and curretage for termination of pregnancy in the first trimester. Patients were excluded from study if they had been receiving any beta adrenergic blockers or psychotropic agents including benzodiazepines, or whose command of English was inadequate to complete the questionnaire.

\section{Preoperative assessment}

\section{ANXIETY}

Preoperative anxiety was measured using the Spielberger State-Trait Anxiety Inventory (STAI). ${ }^{5}$ The STAI is a standardized psychomotor test composed of 40 questions that patients answer using a four-point Likert scale. Twenty of the responses are totaled to give the Trait anxiety score, a measure of baseline tendencies towards anxiety independent of the subject's current situation. The remaining $\mathbf{2 0}$ questions yield the State anxiety score and reflect situational anxiety. The STAI has been used to measure normal preoperative anxiety. ${ }^{6}$

\section{COGNITIVE FUNCTION}

The digit span test is a subset of the Wechsler Intelligence Scale and measures ability to repeat a series of numbers from memory. ${ }^{7}$ Fourteen numbers of increasing length from three to nine digits are read aloud to the subject at a rate of one digit per second. The subject repeats each number from memory immediately after its presentation until all 14 numbers have been correctly completed or until both numbers of a given length are incorrectly recalled. The subject must then repeat a similar set of numbers in reverse order from their original presentation. The total score on the digit span test is the sum of the number of correct responses on forward and reverse testing. Different sets of numbers were used during repeated testing of a single patient.

\section{SENSORY MOTOR TESTING}

The Trieger test is an adaptation of the Bender Motor Gestalt Test which requires both perceptual ability and motor coordination. ${ }^{8}$ The patient is presented with a pattern of dots and asked to join the dots with maximal precision. Two scores result from the Trieger test, one for the number of dots missed and one for the total aggregate deviation by which the dots were missed.

On admission to hospital, approximately two to three hours before surgery, patients completed the STAI-State and Trait, digit span, and Trieger tests and vital signs were recorded. The anaesthetic preoperative interview was conducted immediately after the test battery. A random number table was used to allocate the patients in doubleblind fashion to receive one of the following three medications:

Group 1 = diazepam $10 \mathrm{mg}(n=31)$

Group 2 = propranolol $80 \mathrm{mg}(n=31)$

Group $3=$ placebo $(n=30)$

Tablets were of similar colour and administered orally. Each patient was told that there was approximately a one in three chance that they would receive a placebo containing no active medication. The STAI-State test was repeated in the holding area immediately before entering the operating room $60-90 \mathrm{~min}$ after administration of the medication.

\section{Anaesthetic}

The anaesthetic technique was standardized to include fentanyl $0.5 \mu \mathrm{g} \cdot \mathrm{kg}^{-1}$, thiopentone $5 \mathrm{mg} \cdot \mathrm{kg}^{-1}$ plus an additional $I \mathrm{mg} \cdot \mathrm{kg}^{-1}$ prior to dilatation of the cervix, and pitocin ten units during the curretage. The mask anaesthetic was maintained with $60 \%$ nitrous oxide in oxygen and enflurane titrated to signs of light anaesthesia during spontaneous respiration.

\section{Postoperative assessment}

Vital signs, digit span, and Trieger test results were recorded hourly for three hours postoperatively. The STAI-State assessment was repeated two hours postoperatively.

Statistical analysis of the parametric data included analysis of variance among groups and repeated measures analysis of variance within groups. The STAl data were treated as nonparametric and analyzed with the nonparametric $t$ test and the Kruskal-Wallis test. A P value of 0.05 or less was considered to be significant.

\section{Results}

There were no differences among the three medication groups with respect to age, weight, baseline performance prior to the administration of the premedication on the STAI-State and Trait, digit span, and Trieger tests, or duration of surgery (Table). Eight patients who were asked to consent and would have been eligible to participate in the study declined to consent after an explanation of the study procedure. 
TABLE Patient demographics

\begin{tabular}{|c|c|c|c|c|c|c|}
\hline \multirow[b]{2}{*}{ Age $(y r)$} & \multicolumn{2}{|c|}{$\begin{array}{l}\text { Diazepam } \\
n=31\end{array}$} & \multicolumn{2}{|c|}{$\begin{array}{l}\text { Propranolol } \\
n=31\end{array}$} & \multicolumn{2}{|c|}{$\begin{array}{l}\text { Placebo } \\
n=30\end{array}$} \\
\hline & 23 & (5.3) & 25 & (4.9) & 23 & $(6.0)$ \\
\hline Weight (kg) & 60 & $(10.1)$ & 63 & (16) & 60 & (9.6) \\
\hline $\begin{array}{l}\text { STAI-Trail } \\
\text { (admission) }\end{array}$ & 40 & (8.8) & 39 & (11) & 40 & (II.5) \\
\hline $\begin{array}{l}\text { STAI-State } \\
\quad \text { (admission) }\end{array}$ & 49 & $(12.5)$ & 50 & $(12.3)$ & 49 & $(9.4)$ \\
\hline $\begin{array}{l}\text { Anaesth. duration } \\
\text { (min) }\end{array}$ & & $(2.2)$ & & $(2.0)$ & & $(2.7)$ \\
\hline
\end{tabular}

Mean \pm SD.

Anxiety as measured by the STAI-State assessment showed a steady decrease over time in all three medication groups from admission to discharge (Figure 1). Significant reductions in anxiety between admission and the immediate preoperative period were demonstrated in all medication groups (nonparametric paired $\mathrm{t}$ tests $P<$ 0.05 ). The STAI-State test, when repeated two hours postoperatively, revealed a significant reduction from admission anxiety in all three medication groups $(P<$ $0.0001)$. There were no differences in anxiety scores among the groups at any time period.

Analysis of within group digit span test results showed significant impairment of digit span test results at one hour postoperatively in the diazepam and placebo groups (Figure 2). Repeated exposure of subjects to digit span testing, even with different numbers used in the test, might be anticipated to produce an improvement in strategy for digit recall and therefore an improvement over baseline scores. Many subjects were noted to be grouping numbers together after some experience with the test. Improvement in digit span performance in digit span testing was evident in patients receiving propranolol at two hours postoperatively, but required three hours for the placebo group and was not evident in patients who had received diazepam. The Trieger test is not difficult for the unimpaired subject and therefore offers little room for improvement over baseline scores. In all groups, the Trieger test showed significant impairment at one hour postoperatively both in the number of dots missed and the cumulative deviation (Figure 3, Figure 4). Patients receiving propranolol returned to baseline performance level by two hours after surgery while the patients in the placebo and diazepam groups required three hours.

The haemodynamic data (Figure 5, Figure 6) showed no deviations and there were no untoward events which would preclude using any of these medications on a healthy population such as the outpatients in our study. The lowest heart rate seen in the study was 40 beats $\cdot \mathrm{min}^{-1}$ in a patient who received propranolol. Baseline mea-

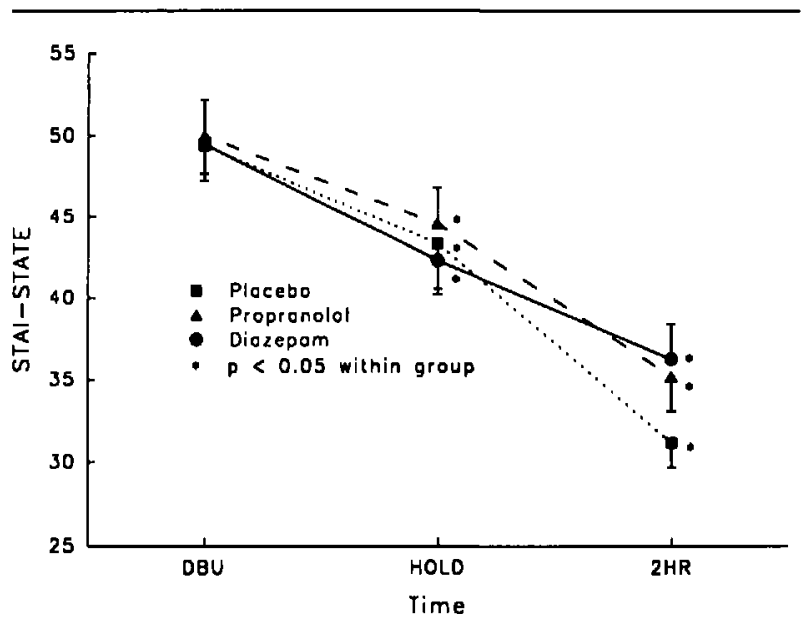

FIGURE I State Trait Anxiely Index scores by medication group over time. DBU = in the day bed unit shortly after admission to hospital. HOLD $=$ in holding area prior to entering the operating room. ZHR $=\mathbf{t w o}$ hours after completion of the operation.

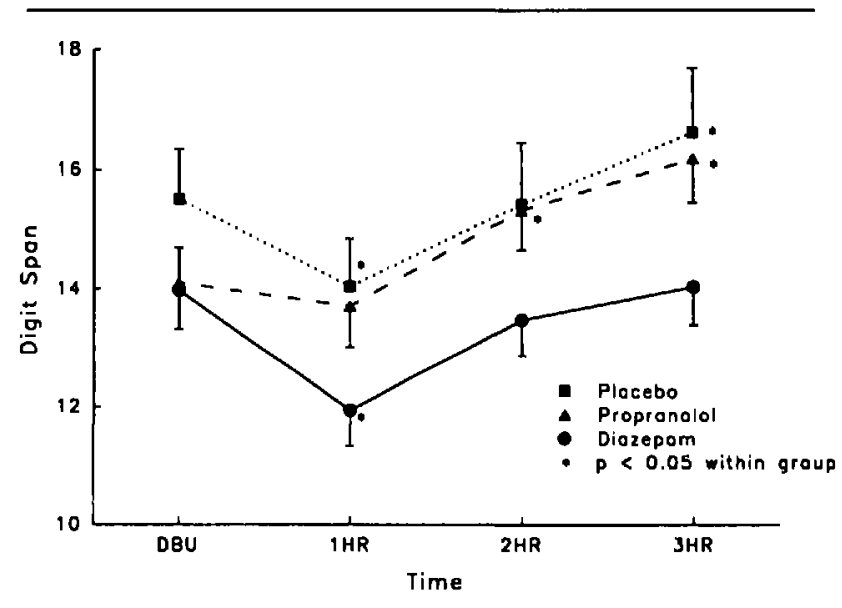

FIGURE 2 Digit Span test scores ( \pm SEM) by medication group over time. $\mathrm{DBU}=$ in the day bed unit shorly after admission to hospital. 1HR 2 HR 3HR = one, two and three hours after completion of the operation.

surements of heart rate and blood pressure showed no difference among groups. The lower heart rate after administration of propranolol was statistically significant and may have prompted the anaesthetist to use a lower inspired enflurane concentration during the maintenance phase of anaesthesia.

\section{Discussion}

Beta adrenergic blockers have been used successfully in the treatment of anxiety neurosis. ${ }^{9,11}$ The beta adrenergic blockers have also been effective in the relief of anxiety during public speaking ${ }^{12}$ stage fright ${ }^{1}$ and competitions. ${ }^{13}$ 


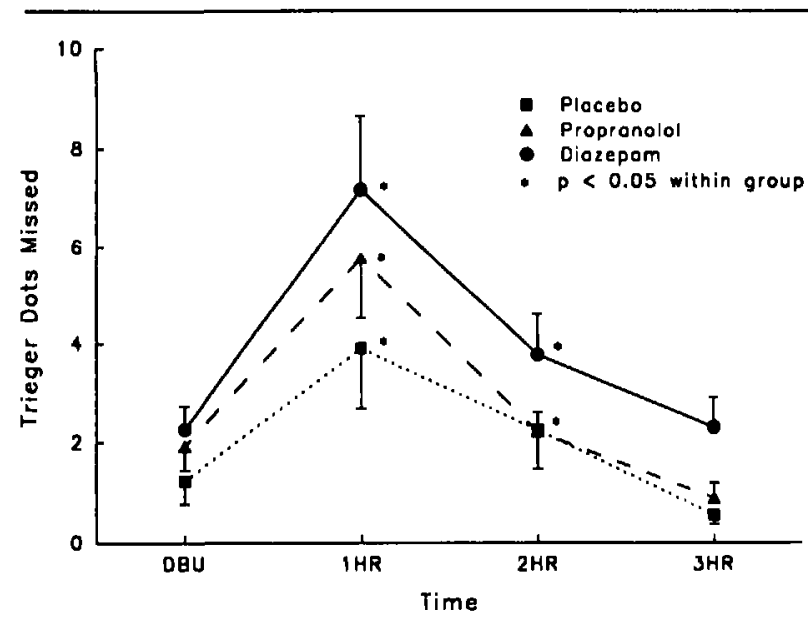

FIGURE 3 Trieger Test number of dots missed ( \pm SEM) by medication group over time. $\mathrm{DBU}=$ in the day bed unit shortly after admission to hospital. IHR 2HR 3HR $=$ one, I wo and three hours after completion of the operation.

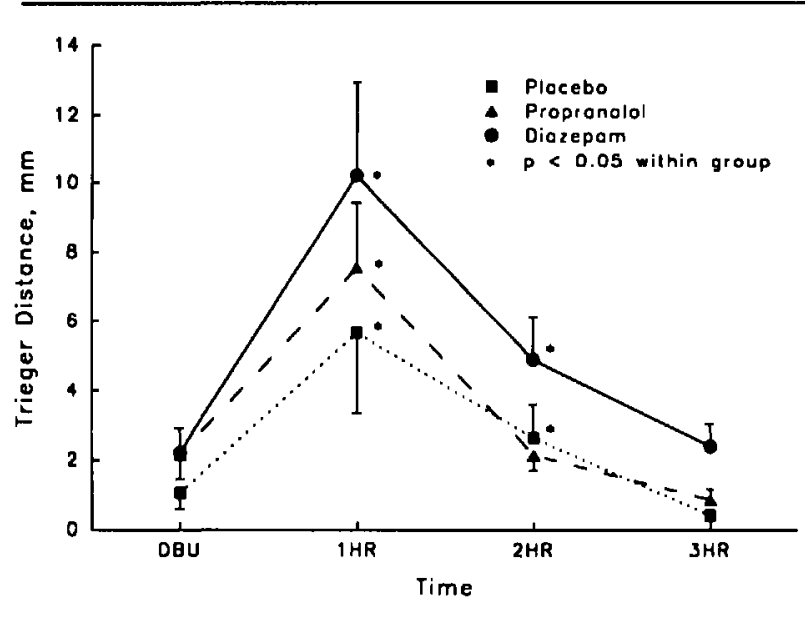

FIGURE 4 Trieger Test aggregate distance missed in millimeters ( \pm SEM) by medication group over time. DBU $=$ in day bed unit shortly after admission to hospital. IHR $2 H R 3 H R=$ one, Iwo and three hours after completion of the operation.

We examined the feasibility of using propranolol as a nonsedating anxiolytic premedication in an outpatient population to block both the measurable symptoms of preoperative anxiety and the anxiety itself.

The secondary manifestations of anxiety (tachycardia and hypertension) are not a serious health hazard in healthy patients who have normal coronary perfusion. Heart rate is a major determinant of diastolic filling time and oxygen consumption, hence it is not surprising that beta adrenergic blockers have demonstrable cardioprotective properties in the perioperative period. ${ }^{14}$

Results of this study reveal that in the preoperative

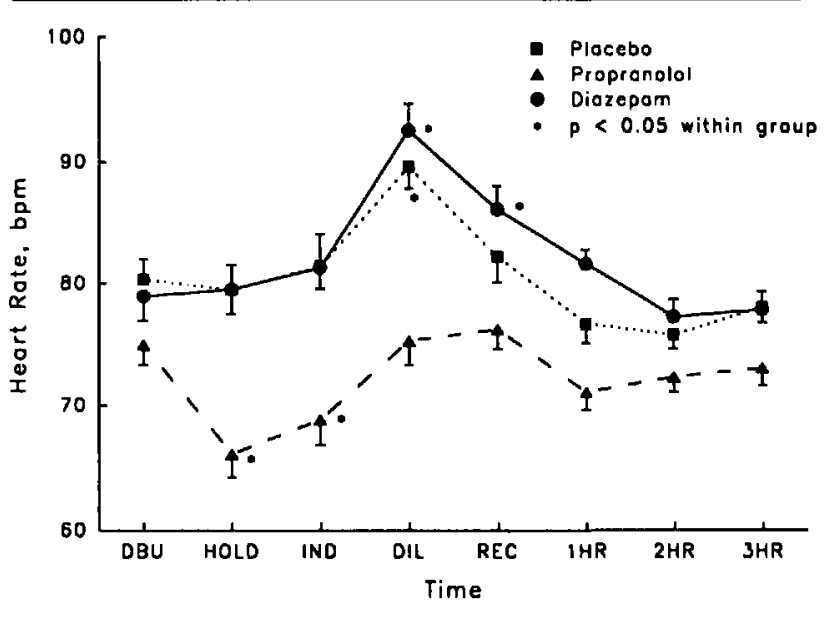

FIGURE 5 Heart Rate ( \pm SEM) by medication group over time. DBU $=$ in day bed unit shortly after admission to hospital. HOLD $=$ in holding area prior to entering the operating room. IND $=$ prior to induction of anaesthesia. DIL $=$ during dilatation of the cervix. REC $=$ on admission to the recovery room. IHR 2HR 3HR = one, two and three hours after completion of the operation.

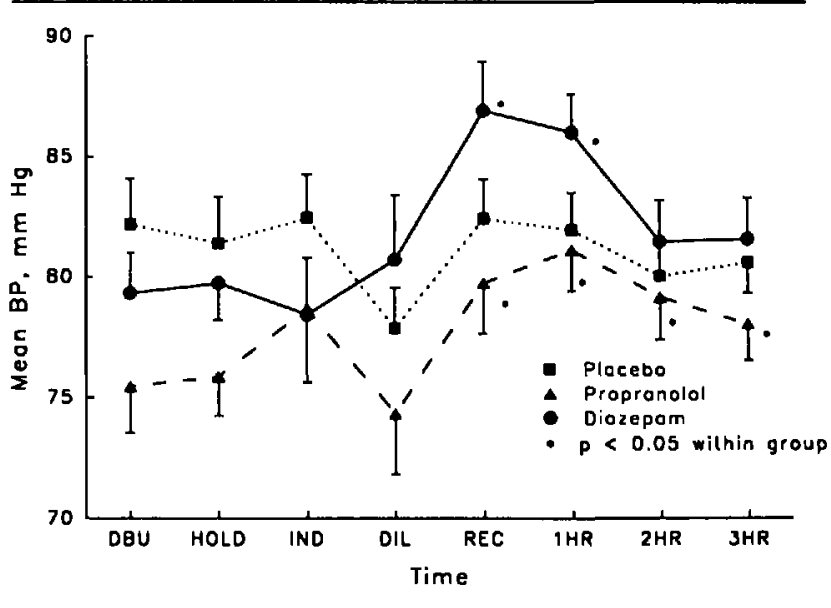

FIGURE 6 Blood Pressure ( \pm SEM) by medication group over time. DBU $=$ in day bed unit shortly after admission to hospital. HOLD $=$ in holding area prior to entering the operating room. IND $=$ prior to induction of anaesthesia. DIL $=$ during dilatation of the cervix.

REC $=$ on admission to the recovery room. IHR 2HR 3HR = one, two and three hours after completion of the operation.

period, propranolol, diazepam, and placebo are all equally effective anxiolytic agents. It has been shown previously that the process of obtaining informed consent introduces a sampling bias against more anxious patients. ${ }^{15}$ This would decrease the overall sensitivity of the study but should be consistent across the three different patient groups.

Psychomotor recovery assessed with the Trieger and digit span tests is slightly faster when the patients received 
propranolol. Repeated measures analysis of variance on samples of 30 patients is a very sensitive test and will label as significant points with small deviations from baseline measurements. The consistent results on all our psychomotor tests suggests that the differences two hours postoperatively, although small, are real. A goal of outpatient anaesthesia is a quick return of cognitive function. From this standpoint administering a centrally acting sedative premedication is counter-productive. It would be difficult to cause less CNS depression than a placebo, but possibly by lowering intraoperative anaesthetic requirements, beta adrenergic blockade speeds up postoperative cognitive recovery. Enflurane uptake from a circle system over a six-minute period would be quite small and a similar study using procedures with a longer operative duration would accentuate any difference in maintenance anaesthetic requirements.

The STAI-State measurements of our study sample on admission were higher than norms obtained from unstressed age and sex matched populations which show adult working females to have a State anxiety score of $35.20 \pm 10.61$ and a Trait anxiety score of $34.79 \pm 9.22$ (mean $\pm \mathrm{SD}$ ). We attribute this deviation to normal preoperative anxiety. Our anxiety scores were similar to previous anxiety measurements on the same patient population. ${ }^{16}$ We had anticipated a peak in anxiety scores prior to induction of anaesthesia, and the steady decline in anxiety throughout the hospital stay may reflect repeated visits by the same investigator, providing a feeling of continuity of care and support. The process of data collection may have influenced the results through distracting the patients from their current situation with numerous tests and attention. The decrease in anxiety as the operation approached may also indicate relief that the operation was proceeding as planned and was unrelated to any premedication. The addition of a fourth group to our study, who received no tablets at all, would have helped to separate the anxiolytic strength of the placebo effect from no treatment.

Our study sample may have been experiencing emotional stress due to the nature of the procedure. Anxiety from different origins such as concerns for physical safety or the possibility of malignancy may not respond equally to standard anxiolytic agents. The STAI does not differentiate between various sources of anxiety.

We could not demonstrate a difference between the efficacy of diazepam and placebo tablets in relief of preoperative anxiety. Several studies have found medications from the benzodiazepine family to have demonstrable anxiolytic properties in the preoperative period ${ }^{17,20}$ while others have found the benzodiazepines to have no greater anxiolytic effect than placebo. ${ }^{21,27}$ Benzodiazepines may differ in their relative potency of anxiolytic, amnesic, and CNS depressant properties. In comparison with diazepam, triazolam is felt to have greater amnesic and sedative properties while showing less effect on anxiety. ${ }^{28}$ In placebo-controlled studies using variable doses of midazolam ${ }^{29}$ and either triazolam or diazepam ${ }^{30}$ it was found that only the largest doses of these medications produced measurable anxiolysis while psychomotor impairment was evident at lower doses. One might question whether the specific anxiolytic effect attributed to the benzodiazepines in their role as anaesthetic premedications is not merely a result of generalized CNS depression.

In conclusion, propranolol, diazepam, and placebo in the doses used for this study all have the same effectiveness in the relief of preoperative anxiety. Diazepam causes postoperative psychomotor impairment and offers no clear anxiolytic advantage. Propranolol is not a superior anxiolytic to diazepam or placebo but does appear to offer a faster return of cognitive function postoperatively.

\section{References}

1 James IM, Pearson RM, Griffith DNW, Newbury

$P$. Effect of oxprenolol on stage-fright in musicians. Lancet 1977; 2: 952-4.

2 Granville-Grossman $K L$, Turner $P$. The effect of propranolol on anxiety. Lancet 1966; 1: 788-90.

3 Betts TA, Knight R, Crowe A, Blake A, Harvey A, Mortiboy $D$. Effect of beta blockers on psychomotor performance in normal volunteers. Eur J Clin Pharmacol 1985; 28: 39-49.

4 Brantigan CO, Brantigan TA, Joseph N. Effect of beta blockade and stimulation of stage fright. Am J Med 1982; 72: 88-94.

5 Spielberger $C D$, Gorsuch RL, Lushene R, Vagg PR, Jacobs GA. Manual for the State-Trait Anxiety Inventory Form Y ("Self Evaluation Questionnaire"). Palo Alto, Consulting Psychologists Press, 1983.

6 Spielberger CD, Auerbach SM, Wadsworth AP, Dunn TM, Taulbee ES. Emotional reactions to surgery. J Consult Clin Psychol 1973; 40: 33-8.

7 Lezak MD. Neuropsychological Assessment. Oxford University Press. 1983; 266-70.

8 Newman $M G$, Trieger $N$, Miller JC. Measuring recovery from anesthesia - a simple test. Anesth Analg 1969; 48: 136-40.

9 Tyrer PJ, Lader $M H$. Response to propranolol and diazepam in somatic and psychic anxiety. BMJ 1974; 2 : 14-6.

10 Burrows GD, Davies B, Fail L, Poynton C, Stevenson $H$. A placebo controlled trial of diazepam and oxprenolol for anxiety. Psychopharmacology 1976; 50: 177-9.

II Wheatley $D$. Comparative effects of propranolol and 
chlordiazepoxide in anxiety states. Br J Psychiatry 1969; 115: 1411-2.

12 Hartley LR, Ungapen S, Davie I, Spencer DJ. The effect of beta adrenergic blocking drugs on speakers' performance and memory. Br J Psychiatry 1983; 142: 512-7.

13 Siitonen L, Sonck $T$, Jänne J. Effect of beta-blockade on performance: use of beta-blockade in bowling and in shooting competitions. J Int Med Res 1977; 5: 359-66.

14 Chung F, Houston PL, Cheng DCH et al. Calcium channel blockade does not offer adequate protection from perioperative myocardial ischemia. Anesthesiology 1988; 69: 343-7.

15 Antrabus JHL. Anxiety and informed consent. Anaesthesia 1988; 43: 267-9.

16 Arellano $R$, Cruise $C$, Chung $F$. Timing of the anesthetist's preoperative outpatient interview. Anesth Analg 1989; 68: 645-8.

17 Male CG, Lim YT, Male M, Stewart JM, Gibbs JM. Comparison of three benzodiazepines for oral premedication in minor gynaecological surgery. $\mathrm{Br} J$ Anaesth 1980; 52: 429-35.

18 Jakobsen H, Heriz JB, Johansen JR, Hansen A, Kolliker $K$. Premedication before day surgery. $\mathrm{Br} \mathrm{J}$ Anaesth 1985; 57: 300-5.

19 Raeder JC, Breivik H. Premedication with midazolam in out-patient general anaesthesia. A comparison with morphine-scopolamine and placebo. Acta Anaesthesiol Scand 1987; 31: 509-14.

20 Shafer A, White PF, Urquhart ML, Doze VA. Outpatient premedication: use of midazolam and opioid analgesics. Anesthesiology 1989; 71: 495-501.

21 Assaf RAE, Dundee JW, Bali IM. Studies of drugs given before anaesthesia XXV: medazepam, a new benzodiazepine. Br J Anaesth 1975; 47: 464-7.

22 Forrest $W H$, Brown $C R$, Brown $B W$. Subjective responses to six common preoperative medications. Anesthesiology 1977; 47: $241-7$.

23 Simpson KH, Dearden MJ, Ellis FR, Jack TM. Premedication with slow release morphine (MST) and adjuvants. Br J Anaesth 1988; 60: 825-30.

24 O'Boyle CA, Barry H, Fox E, McCreary C, Brewley $A$. Controlled comparison of a new sublingual lormetazepam formulation and IV diazepam in outpatient minor oral surgery. Br J Anaesth 1988; 60: 419-25.

$25 O^{\prime}$ Boyle CA, Harris D, Barry H, McCreary C, Brewley A, Fox $E$. Comparison of midazolam by mouth and diazepam IV in outpatient oral surgery. Br J Anaesth 1987; 59: 746-54.

26 Artru AA, Dhamee MS, Seifen AB, Wright B. A reevaluation of the anxiolytic properties of intramuscular midazolam. Anaesth Intensive Care 1986; 14: 152-7.
27 Forrest $P$, Galletly $D C$, Yee $P$. Placebo controlled comparison of midazolam, triazolam and diazepam as oral premedicants for outpatient anaesthesia. Anaesth Intensive Care 1987; 15: 296-304.

28 Pinnock CA, Fell D, Hunt PCW, Miller R, Smith G. A comparison of triazolam and diazepam as premedication agents for minor gynaecological surgery. Anaesthesia 1985; 40: 324-8.

29 Raybould D, Bradshaw EG. Premedication for day case surgery. Anaesthesia 1987; 42: 591-5.

30 Baughman VL, Becker GL, Ryan CM, Glaser M, Abenstein $J P$. Effectiveness of triazolam, diazepam, and placebo as preanesthetic medications. Anesthesiology 1989; 71 : 196-200. 